\title{
Case series: Monocular visual loss associated with subarachnoid hemorrhage secondary to ruptured intracranial aneurysms
}

\author{
[Perte visuelle monoculaire associée à une hémorragie sous-arachnoïdienne secon-
} daire à la rupture d'anéprysmes intracrâniens]

Chin Ted Chong mbBs, ${ }^{*} \mathrm{Ki}$ Jinn Chin mmed(anaes), ${ }^{*}$ Leonard W. Yip mrcsed mmed(ophth), $\dagger$ Kulgit Singh MMED(ANAES)*

Purpose: To describe variations in the presentation of monocular visual loss associated with intracranial aneurysm rupture. The clinical course, possible etiologies and management of visual loss in three patients are described.

Clinical features: The first patient developed Terson's syndrome (vitreal hemorrhage associated with raised intracranial pressure secondary to subarachnoid hemorrhage). Following aneursymal clipping, her postoperative management was conservative and there was no improvement in visual acuity. The second patient underwent surgical clipping of internal carotid aneursysms and sustained visual loss subsequent to surgical dissection and temporary clipping around the optic nerve and anterior choroidal artery. The vessel subsequently thrombosed. Potential contributing factors to visual loss in this case included intraoperative hypotension and anemia. This patient received anti-platelet medications, and experienced subsequent improvement in visual acuity to 6/9. A third patient underwent a right orbito-frontal keyhole craniotomy with the cranial flap retracted across the orbit. Elevated intraocular pressure secondary to external orbital compression may have compromised retinal and choroidal perfusion. This patient also developed vasospasm of both anterior cerebral arteries which resolved partially with papaverine therapy. Hypertensionhypervolemia therapy was instituted, with subsequent partial recovery of visual acuity in her right eye.

Conclusion: Perioperative monocular visual loss associated with intracranial aneurysm repair is an infrequent occurrence, and clinical presentations may be quite variable. The primary pathophysiological mechanisms are intraocular hemorrhage and ischemia of ocular structures, including the optic nerve. Early detection, via regular fundoscopic examination and treatment aimed at decreasing intraocular pressure and augmenting ocular perfusion may improve outcomes.
Objectif: La perte visuelle monoculaire associée à la rupture anévrysmale intracrânienne peut se présenter de diverses façons. Le cas de trois patients est décrit selon le tableau clinique, les causes possibles et le traitement de la perte visuelle.

Éléments cliniques: Chez la première patiente un syndrome de Terson s'est développé (hémorragie vitréenne associée à une hypertension intracrânienne secondaire à une hémorragie sous-arachnoïdienne). Après la ligature anévrysmale, le traitement postopératoire conservateur administré n'a pas amélioré l'acuité visuelle. Le second patient a subi une ligature chirurgicale d'anévrysmes de la carotide interne et une perte visuelle permanente consécutive à la dissection chirurgicale et au clip temporaire autour du nerfoptique et de l'artère choroïdienne antérieure. Une thrombose est survenue ensuite dans ce vaisseau. Dans ce cas, les facteurs potentiels de la perte visuelle comprennent l'hypotension et l'anémie peropératoires. Le patient a reçu des anti-plaquettaires qui ont amélioré l'acuité visuelle à 6/9. Un troisième patient a subi une craniotomie orbito-frontale à incision minimale où le lambeau crânien a été rabattu sur l'orbite. L'élévation intra-oculaire de la pression, secondaire à la compression orbitale externe, peut avoir compromis la perfusion rétinienne et chorödienne. Un vasospasme des deux artères cérébrales antérieures s'est aussi développé, résorbé partiellement avec la papavérine. Un traitement de l'hypertension-hypervolémie a été institué, suivi d'une récupération partielle de l'acuité visuelle de l'œil droit.

Conclusion : La perte visuelle monoculaire périopératoire associée à la réparation d'un anévrysme intracrânien survient rarement et son tableau clinique peut varier. Les mécanismes physiopathologiques principaux en sont l'hémorragie intra-oculaire et l'ischémie des structures oculaires, dont le nerf optique. La détection précoce, par l'examen régulier du fond de l'œil, et le traitement visant à réduire la pression intra-oculaire et à augmenter la perfusion oculaire peuvent améliorer la situation.

From the Department of Anesthesiology, ${ }^{*}$ The Eye Institute, $†$ Tan Tock Seng Hospital, National Healthcare Group, Singapore. Address correspondence to: Dr. Chin Ted Chong, Department of Anesthesiology, Tan Tock Seng Hospital, 11 Jalan Tan Tock Seng,

Singapore 308433. Phone: 65-63577771; Fax: 65-63577772; E-mail: chintedchong@yahoo.com.sg Accepted for publication December 16, 2005.

Revision accepted February 28, 2006.

Competing interests: None declared. 
$\mathrm{B}$ LINDNESS is an uncommon but devastating complication of anesthesia and surgery. Routine screening for visual symptoms and signs in high-risk patient populations facilitates early detection, allowing appropriate emergency care to be instituted promptly. Perioperative blindness may be associated with cardiac or complex spine surgery, and the risk factors in these settings are welldescribed. ${ }^{1,2}$

Perioperative visual loss, although less well-recognized, can develop in patients undergoing surgery for ruptured intracranial aneurysms. We report three patients who developed monocular visual loss of varying etiologies, but all following intracranial aneurysmal rupture. The etiology and time course from initial rupture of the aneurysm to the development of visual loss differed in all three patients. Visual loss occurred prior to surgery in one patient, developed shortly after surgery in another, and presented six days after clipping of the aneurysm in the third patient. We describe the development and management of visual loss in these patients, and review the underlying neurovascular-ophthalmic pathophysiological mechanisms. Consent for publication of these cases was obtained from the individual patient or the caregiver, in accordance with our institutional guidelines.

\section{Case reports}

Case 1

A 44-yr-old female tourist was admitted to hospital with acute severe headache and vomiting. She had pre-existing hypertension controlled with atenolol, amlodipine, losartan and bendrofluazide. A left subarachnoid hemorrhage $(\mathrm{SAH})$ was diagnosed on a computerized tomographic (CT) head scan, and she was transferred to the neurosurgical intensive care unit for further management. On admission her Glasgow coma score (GCS) was 13. She had expressive dysphasia but no motor or visual deficits. Cerebral angiography revealed a single aneurysm at the bifurcation of the left middle cerebral artery. As it was not amenable to endovascular coiling she was scheduled for emergency clipping of the aneurysm. Surgery was delayed because of significant hypokalemia, and while undergoing preoperative correction of her electrolytes, she complained of sudden painful loss of vision in her left eye, approximately $48 \mathrm{hr}$ after initial aneurysmal rupture. Visual examination of the left eye revealed loss of acuity in the superior visual field to counting fingers only, and complete blindness in the lower visual field. There was also loss of vision to counting fingers only in the right eye. The attending ophthalmologist documented papilledema, a large subretinal hemorrhage and a small vitreous hemorrhage in the left eye on fundoscopy, and a diagnosis of Terson's syndrome was made. There was a small blot hemorrhage in the retina of the right eye. Intraocular pressure was normal in both eyes. An urgent CT head scan showed no new changes, hydrocephalus or midline shift.

The patient underwent successful clipping of the aneurysm the same day via a left pterional approach. General anesthesia, using propofol $150 \mathrm{mg}$ iv and fentanyl $200 \mu \mathrm{g} i v$ for induction, and isoflurane and nitrous oxide for maintenance, was uncomplicated. The patient was kept normotensive throughout the procedure, estimated blood loss was 100-200 mL, and the postoperative hemoglobin was $10.9 \mathrm{~g} \cdot \mathrm{dl}^{-1}$. An external ventricular drain was inserted for control of intracranial pressure. Hypervolemic-hypertensive therapy to maintain systolic blood pressure above $180 \mathrm{mmHg}$ using norepinephrine infusion up to 0.1 $\mu \mathrm{g} \cdot \mathrm{kg}^{-1} \cdot \mathrm{min}^{-1}$ was instituted post-aneurysmal clipping, and the patient's trachea was extubated on the second postoperative day. At ophthalmological review on the $12^{\text {th }}$ postoperative day, the right retinal hemorrhage had resolved, but there was a dense breakthrough vitreous hemorrhage in the left eye, completely obscuring any view of the fundus. Visual acuity in the left eye was limited to light perception only. An ultrasound scan excluded the presence of retinal detachment. The patient was managed conservatively with bed rest and head elevation. No further improvement in vision was documented during her hospital stay. She returned to her country of origin on the $14^{\text {th }}$ postoperative day for further care, and was subsequently lost to follow-up.

Case 2

A 51-yr-old hypertensive female (controlled on diuretic therapy) presented with a two-day history of giddiness, mild headache and coffee-ground vomiting. This was initially diagnosed as a bleeding peptic ulcer. Her GCS, however, deteriorated from 15 to 7 several hours after admission. An urgent CT scan of the head showed extensive SAH with intraventricular extension and hydrocephalus. She underwent emergent insertion of a right frontal external ventricular drain and her postoperative GCS improved to 15 . The first cerebral angiogram was reported as normal, but a second angiogram done three days later revealed two left internal carotid aneurysms, arising on either side of the origin of the anterior choroidal artery. The patient underwent surgical clipping of the aneurysms via the pterional approach five days after initial onset of symptoms. Hemodynamic stability was maintained during induction of anesthesia and subsequent surgical dissection. The surgeon was able to visualize and 
preserve both the optic nerve and anterior choroidal artery. A bolus of thiopental $250 \mathrm{mg}$ iv was administered for cerebral protection prior to application of temporary clips. This resulted in a transient decrease in blood pressure from $120 / 65 \mathrm{mmHg}$ to $95 / 54$ $\mathrm{mmHg}$. The hypotension was corrected with ephedrine $10 \mathrm{mg} i v$. There were no other episodes of significant hypotension requiring vasopressor therapy. Permanent clipping of both aneurysms was achieved without further complications. The estimated blood loss was $600 \mathrm{~mL}$, and the postoperative hemoglobin was $9.8 \mathrm{~g} \cdot \mathrm{dl}^{-1}$.

The patient's trachea was extubated at the end of the procedure. Immediate postoperative examination in the neurosurgical intensive care unit revealed a left relative afferent pupillary defect. Visual testing of the left eye revealed complete visual loss in the temporal half of the visual field and detection of hand movement only in the nasal half. Visual testing of the right eye was normal. Fundoscopy of the left eye showed retinal edema in the distribution of the cilioretinal artery, and the supero-nasal and inferio-nasal branch retinal arteries. A clinical diagnosis of left cilioretinal artery occlusion and branch retinal artery occlusion was made, with the possible etiologies being emboli or vasospasm. Arterial perfusion had recovered by the time of the examination. A carotid ultrasound and echocardiogram did not reveal an embolic source for the occlusion. The patient was nevertheless started on acetylsalicylic acid $100 \mathrm{mg}$ po daily. On the third postoperative day therapy was converted to ticlopidine $250 \mathrm{mg}$ po bid. An infusion of norepinephrine 0.1 $\mu \mathrm{g} \cdot \mathrm{kg}^{-1} \cdot \mathrm{min}^{-1}$ was started $11 \mathrm{hr}$ postoperatively, and continued for five days, as part of routine hypertensive-hypervolemic therapy. Serial transcranial Doppler (TCD) studies were negative for vasospasm, and no other neurological deficits were identified. Three days after the onset of monocular visual loss, her vision had improved to counting fingers from a distance of one meter in all quadrants of her left eye. At review six months later, her visual acuity had improved to 6/9 with a residual left temporal scotoma and optic atrophy. Further recovery was deemed unlikely.

\section{Case 3}

A 33-yr-old female patient with pre-existing but untreated hypertension presented with sudden onset of severe headache associated with neck stiffness and vomiting. She had a systolic blood pressure $>200$ $\mathrm{mmHg}$ and a GCS of 14. She had no motor or visual deficits. A left fronto-parietal SAH was confirmed on CT head scan and a cerebral angiogram revealed a saccular aneurysm at the junction of the $\mathrm{Al}$ and
A2 segments of the right anterior communicating artery. She was started on nimodipine $2 \mathrm{mg} \cdot \mathrm{hr}^{-1}$ $i v$, and underwent clipping of the aneurysm $24 \mathrm{hr}$ after admission. Surgery was performed through a right orbito-frontal incision. Under anesthesia with thiopentone $200 \mathrm{mg}$ iv for induction and isoflurane and nitrous oxide for maintenance, hemodynamic stability was maintained until the aneurysm ruptured two hours into surgery. Blood pressure remained stable with supplemental normal saline $500 \mathrm{~mL}$ and $6 \%$ hydroxyethyl starch (Haesteril) $500 \mathrm{~mL}$ infusing concurrently with ongoing blood loss, and the lowest recorded systolic blood pressure was $120 \mathrm{mmHg}$. No vasopressors were required. Temporary clips were applied for four minutes before permanent clipping was achieved. Estimated blood loss was $300 \mathrm{~mL}$ with a fall in hemoglobin concentration from $13.4 \mathrm{~g} \cdot \mathrm{dl}^{-1}$ to $11.9 \mathrm{~g} \cdot \mathrm{dl}^{-1}$. The patient's trachea was extubated postoperatively, and she had a GCS of 14-15. Prophylactic hypertensive-hypervolemic therapy was not started, although she continued to receive nimodipine and systolic blood pressure was maintained between 130-160 $\mathrm{mmHg}$ without the use of vasopressors. The central venous pressure was $10-12 \mathrm{~cm} \mathrm{H}_{2} \mathrm{O}$. Serial TCD studies initially showed a high peak flow velocity of $118 \mathrm{~cm} \cdot \mathrm{sec}^{-1}$ in the right anterior cerebral artery on the first postoperative day, but values decreased to 90 and $108 \mathrm{~cm} \cdot \mathrm{sec}^{-1}$ on the second and third postoperative days, respectively.

This patient's postoperative course remained uneventful until the fifth postoperative day, when she complained of sudden visual loss in her right eye. Ophthalmological examination confirmed complete visual loss in the right eye with a relative afferent pupillary defect, while the left eye examination was normal. A CT head scan showed only a small infarct of the left caudate nucleus. A presumptive diagnosis of posterior ischemic optic neuropathy (ION) was made, and an urgent cerebral angiogram was performed within six to seven hours of onset of blindness. This showed significant vasospasm of the Al segments of both anterior cerebral arteries. Papaverine $100 \mathrm{mg}$ was infused directly into the right anterior cerebral artery and this produced an immediate increase in vessel caliber. Hypertensive-hypervolemic therapy was instituted for four days following the angiogram, with the systolic blood pressure maintained between 180 to $200 \mathrm{mmHg}$ using norepinephrine infusion, the highest rate being $0.08 \mu \mathrm{g} \cdot \mathrm{kg}^{-1} \cdot \mathrm{min}^{-1}$. The next day, the patient's vision in the inferior temporal quadrant of the right eye had improved to counting fingers. Peak velocities in the right anterior cerebral artery remained elevated on serial TCD studies, but normalized on 
the sixth day after onset of visual symptoms. A repeat angiogram on the tenth day after visual loss confirmed that the vasospasm of the anterior cerebral arteries had significantly improved. She was discharged 22 days after first admission. At review six months later, her vision had improved to counting fingers in all quadrants of the right eye. There was optic atrophy consistent with the diagnosis of posterior ION.

\section{Discussion}

The true incidence of perioperative visual loss following SAH and surgical clipping of aneurysms is difficult to determine. However, the occurrence of intraocular hemorrhage in association with SAH is estimated to be between $17 \%{ }^{3}$ and $41 \%{ }^{4}$ The overall incidence of visual loss may be higher, when taking into account other etiologies for visual loss, and the under-reporting which likely occurs as a result of the significant mortality and neurological morbidity associated with the condition. Prompt recognition of visual deficits is vital, as early ophthalmological assessment and appropriate management can influence outcome. However, early clinical diagnosis may be hampered by the inability of patients to communicate, due either to a low GCS or to sedation and postoperative ventilation of select patients.

Apart from structural damage to the parenchyma of the visual pathways and cortex that may occur during the acute bleed, there are two primary pathophysiological mechanisms for visual loss following $\mathrm{SAH}$ and surgical clipping of aneurysms. These include intraocular hemorrhage, and ischemia of ocular structures, including the optic nerve. The timing and the clinical features at presentation will vary according to the underlying cause.

The most common cause of visual loss following $\mathrm{SAH}$, especially in the preoperative phase, is intraocular hemorrhage. Vitreous hemorrhage, experienced by the first patient, accounts for the majority of cases. It was described 100 years ago by Terson, after whom the clinical syndrome is named. Terson's syndrome occurs in up to $8 \%$ of SAH patients and appears to correlate with the clinical severity of the SAH. ${ }^{3}$ There are two postulated mechanisms for intraocular hemorrhage following SAH. Firstly, raised intracranial pressure is transmitted to the subarachnoid space that surrounds the optic nerve, resulting in dilation of the nerve sheath and rupture of dural and bridging vessels. Secondly, obstruction to retinal venous drainage may occur, causing retinal venous hypertension and subsequent vessel rupture. Management is often conservative, as many vitreous hemorrhages spontaneously resolve within one year. The time course and extent of visual recovery is however, extremely variable. ${ }^{4,5}$ Further complications, including cataracts, proliferative vitreoretinopathy, and retinal detachment may also result from the presence of blood in the vitreous. Early vitrectomy may therefore result in better outcome, as well as shorten the time to visual recovery. ${ }^{3}$ In any case, periodic visual testing and ultrasound scans are recommended to monitor clinical recovery, and to detect retinal detachment, respectively.

Ocular ischemia is the other major cause of blindness following $\mathrm{SAH}$ and aneurysm clipping. It may be due to a variety of intraoperative and postoperative factors. The blood supply to the eye is derived entirely from the ophthalmic artery, which arises from the supraclinoid segment of the internal carotid artery, prior to its entry into the Circle of Willis. Its main branches are the central retinal artery, and the ciliary arteries (anterior, long and short posterior). The retina is supplied by the central retinal artery (inner retina) as well as by posterior ciliary arteries (outer retina). Retinal function is dependent on the integrity of both arterial systems. ${ }^{6}$ The macula is also supplied by cilioretinal arteries which arise from the choroidal circulation. These may protect the macula from ischemia during episodes of diminished central retinal artery flow. The intraocular portion of the optic nerve (anterior to the lamina cribrosa) is supplied by the short posterior ciliary arteries via the choriocapillaris (the inner capillary layer of the choroid). Posterior to the lamina cribrosa, the intraorbital optic nerve is supplied by the central retinal artery, as well as by pial vessels originating from the ophthalmic artery. Finally, the intracanalicular and intracranial portions of the optic nerve are supplied by a pial network originating from the internal carotid and anterior cerebral arteries.

Flow in the ophthalmic artery and its branches may be compromised by retraction or inadvertent damage during surgical dissection, as well as by temporary clips placed at or proximal to the origin of the ophthalmic artery. Embolism is a less likely cause, unless there is pre-existing intracardiac thrombus or carotid artery atheroma. Vessel thrombosis may occur following surgical handling or postoperative inflammation and can further compromise flow well into the postoperative period. Hypoperfusion of all branches of the ophthalmic artery with resultant global orbital infarction has been reported following aneurysm surgery. ${ }^{7}$ It is important to be aware of this rare but devastating complication, and to distinguish it from simple postoperative periorbital edema or hematoma, which may also present with proptosis and chemosis. Distinguishing features of orbital infarction include ophthalmoplegia, a relative afferent pupillary defect, and retinal edema without a cherry-red spot. 
It is unusual for ophthalmic artery insufficiency alone to result in orbital infarction, as a collateral circulation exists between the ophthalmic artery and the external carotid artery; there are usually other contributory factors. In other surgical patients, prolonged hypotension, severe anemia, and the use of vasopressors have been implicated as risk factors for perioperative blindness. ${ }^{8,9}$ These may apply in the setting of aneurysmal clipping as well, especially if intraoperative rupture occurs. Direct pressure on the globe, causing raised intraocular pressure (IOP) and subsequent retinal ischemia, is unusual unless the patient is placed in the prone position. However, Zimmerman et al. ${ }^{7}$ reported six patients who underwent a fronto-temporal craniotomy for aneurysmal clipping, and subsequently developed orbital infarction syndrome. This was partly attributed to retraction of the myocutaneous flap over the eye, resulting in globe compression. Changes in intracranial pressure following $\mathrm{SAH}$ and surgery may also contribute to reduced blood flow. Reductions in ophthalmic artery perfusion pressure have been demonstrated in monkeys when intracranial pressure exceeds $35 \mathrm{~cm} \mathrm{H}_{2} \mathrm{O}$, as well as when intracranial pressure falls abruptly. ${ }^{10}$ Finally, impaired orbital venous drainage may also contribute to vascular insufficiency. This can result again from inadvertent surgical trauma (the fronto-temporal surgical approach intersects the path of the large draining veins of the orbit), or postoperative inflammation and thrombosis.

Management of retinal ischemia due to causes such as central retinal artery occlusion and cilioretinal artery occlusion includes ocular massage, anterior chamber paracentesis and the administration of intraocular pressure lowering medications. ${ }^{11}$ Visual prognosis in retinal ischemia is related to the presenting visual acuity and the rapidity of treatment. Management of orbital ischemia includes panretinal photocoagulation to treat neovascularization of the iris, disc and retina. Neovascular glaucoma is a potential complication which may necessitate medical and surgical treatment. Visual prognosis is poor in orbital ischemia despite aggressive treatment.

Ischemic optic neuropathy is the most common cause of postoperative visual loss in general, ${ }^{12,13}$ although the etiology remains incompletely understood. The cause is thought to be multifactorial, and proposed factors include systemic hypotension, anemia from intraoperative blood loss, increased intraocular or orbital venous pressure, systemic vascular disease, and the use of vasopressors. Additional factors to consider in cerebral aneurysm surgery include vasospasm (see below), as well as surgical and ischemic damage to the optic nerve during dissection and tem- porary clipping. The pial network supplying the nerve is especially delicate and may be torn by inadvertent traction on the dura during dissection close to the nerve. Scarring, inflammation, and thrombosis of the vessels may also occur following thermal injury from electrocautery, the use of hemostatic agents such as gelfoam, or simply from the presence of subarachnoid blood. ${ }^{14}$ Management is directed towards increasing perfusion pressure and oxygen-carrying capacity, so as to optimize blood flow to the optic nerve. The prognosis for visual recovery is poor in most cases.

Finally, it should be noted that visual loss may also be a presenting symptom of vasospasm, especially if it occurs in the late postoperative phase. In the third case illustrated above, it is likely that vasospasm of the anterior cerebral artery led to hypoperfusion of the pial network supplying the intracanalicular and intracranial portion of the optic nerve. Vasospasm of smaller arterioles may also occur, but is unlikely to be visible on cerebral angiography. Cerebral vasospasm has a peak incidence three to seven days after the initial SAH and is rare after 14 days. Nimodipine is used primarily as prophylaxis against vasospasm. ${ }^{15}$ If there is evidence of vasospasm, either in the form of elevated TCD flow velocities or new neurological deficits, hypervolemichypertensive-hemodilution (triple- $\mathrm{H}$ ) therapy is the mainstay of treatment. ${ }^{16}$ It is now common in many centres to use triple- $\mathrm{H}$ therapy in a prophylactic role as well, although the evidence of efficacy in this regard is less convincing. Of the three components, hypervolemia is almost always used, and is achieved by infusing iv fluids (crystalloid or colloid) to achieve a central venous pressure of $8-10 \mathrm{~cm} \mathrm{H}_{2} \mathrm{O}$. Deliberate hypertension is also commonly induced using a vasopressor infusion (phenylephrine, dopamine, or norepinephrine being the favoured agents). It should be noted that vasopressor use has been implicated as a contributory factor in ION in critically ill patients, ${ }^{8}$ although its exact effect on optic nerve blood flow remains ill-defined. Hemodilution is the most controversial of the three components, as there is no evidence that a lower than normal hematocrit is beneficial in cerebral ischemia. Blood flow increases at lower blood viscosities, but whether a lower hematocrit results in increased oxygen delivery is questionable. ${ }^{17}$ Given the association between ION and anemia, it is advisable to adopt a passive approach to achieving hemodilution. If clinically significant vasospasm still occurs despite these measures, and the expertise is available, cerebral angiography may be performed with subsequent balloon endovascular therapy (angioplasty or intra-arterial injection of papaverine), in an attempt to reverse visibly stenosed vessels. ${ }^{18,19}$ 
In conclusion, monocular visual loss may be an under-appreciated complication of SAH and surgical clipping of cerebral aneurysms. This can be attributed in part to the decreased consciousness that occurs commonly following both the primary bleed as well as surgery. The anesthetic plan should incorporate drugs which facilitate rapid recovery. Careful ophthalmological examination, including fundoscopy, will facilitate the early diagnosis and management of visual deficits. The etiology of visual loss is varied, as illustrated by the patients in this series, and may be multifactorial. We recommend that symptoms and signs of visual loss should be actively sought, and evaluated at appropriate intervals for all patients with SAH. Regular fundoscopic examinations should be done in patients who are incapable of verbal communication.

\section{References}

I Nuttall GA, Garrity JA, Dearani JA, et al. Risk factors for ischemic optic neuropathy after cardiopulmonary bypass: a matched case/control study. Anesth Analg 2001; 93: 1410-6.

2 Roth S, Thisted RA, Erickson JP, Black S, Schreider $B$. Eye injuries after non-ocular surgery. A study of 60,965 anesthetics from 1988 to 1992 . Anesthesiology 1996; 85: 1020-7.

3 Frizzell RT, Kubn F, Morris R, Quinn C, Fisher WS III. Screening for ocular hemorrhages in patients with ruptured cerebral aneurysms: a prospective study of 99 patients. Neurosurgery 1997; 41: 529-33.

4 Schultz PN, Sobol WM, Weingeist TA. Long-term visual outcome in Terson syndrome. Ophthalmology 1991; 98: 1814-9.

5 Khan SG, Frenkel M. Intravitreal hemorrhage associated with rapid increase in intracranial pressure (Terson's syndrome). Am J Ophthalmol 1975; 80: 37-43.

6 Shaw HE Jr, Landers MB III. Vitreous hemorrhage after intracranial hemorrhage. Am J Ophthalmol 1975; 80: 207-13.

7 Zimmerman CF, Van Patten PD, Golnik KC, Kopitnik $T A J r$, Rajiv A. Orbital infarction syndrome after surgery for intracranial aneurysms. Ophthalmology 1995; 102: 594-8.

8 Lee LA, Nathens AB, Sires BS, et al. Blindness in the intensive care unit: possible role for vasopressors? Anesth Analg 2005; 100: 192-5.

9 Hollenhorst RW, Svien HJ, Benoit CF. Unilateral blindness occurring during anesthesia for neurosurgical operations. AMA Arch Ophthalmol 1954; 52: 819-30.

10 Hayreh SS, Edwards J. Ophthalmic arterial and venous pressures. Effects of acute intracranial hypertension. $\mathrm{Br}$ J Ophthalmol 1971; 55: 649-63.
11 Rumelt S, Brown GC. Update on treatment of retinal arterial occlusions. Curr Opin Ophthalmol 2003; 14: $139-41$.

12 Lee LA. POVL registry reports preliminary data. APSF Newslett 2003; 18: 17-32.

13 Roth S, Gillesberg I. Injuries to the visual system and other sense organs. In: Benumof J, Saidman L (Eds). Anesthesia and Perioperative Complications. St Louis: Mosby; 1999: 377-408.

14 Rizzo JF III. Visual loss after neurosurgical repair of paraclinoida aneurysms. Ophthalmology 1995; 102: 905-10.

15 Allen GS, Ahn HS, Preziosi TJ, et al. Cerebral arterial spasm--a controlled trial of nimodipine in patients with subarachnoid hemorrhage. N Engl J Med 1983; 308: 619-24.

16 Sen J, Belli A, Albon H, Morgan L, Petzoid A, Kitchen $N$. Triple- $\mathrm{H}$ therapy in the management of aneurysmal subarachnoid haemorrhage. Lancet Neurol 2003; 2 : 614-21.

17 Grotta JC. Current status of hemodilution in acute cerebral ischemia (Editorial). Stroke 1987; 18: 689-90.

18 Firlik KS, Kaufmann AM, Firlik AD, Jungreis CA, Yonas $H$. Intra-arterial papaverine for the treatment of cerebral vasospasm following aneurysmal subarachnoid hemorrhage. Surg Neurol 1999; 51: 66-74.

19 Andaluz N, Tomsick TA, Tew JM Jr, van Loveren HR, Yeh HS, Zuccarello M. Indications for endovascular therapy for refractory vasospasm after aneurysmal subarachnoid hemorrhage. Experience at the University of Cincinnati. Surg Neurol 2002; 58: 131-8. 